\title{
Buildings Sustainability — The Non-Intrusive Load-Identification System Contribution
}

\author{
M. Felgueiras, N. Cruz, F. Martins, and R. Martins
}

\begin{abstract}
Buildings are responsible for an important share of the global energy consumed with the associated consequences at economic and environmental level. To overcome this actual concern several objectives were put in perspective, being one of them the energetic performance of systems and appliances. Efficiency depends on working on optimal conditions and user behavior. Monitoring of the energy consumption of each electric load is important but the use of decentralized energy is not feasible at present due to the huge number of loads connected to the electric grid. An alternative consists on the use of a centralized measurement device able to identify loads. This work presents a measurement infrastructure that have, among others, the possibility to make the identification of electrical loads data will be used to improve the energetic performance of households and buildings and increase the sustainability of the energy system.
\end{abstract}

Index Terms-Building sustainability, electric energy, non-intrusive load-identification.

\section{INTRODUCTION}

Energy is a key hot topic to many human activities (industry, agriculture, etc.) that is indispensable to the sustainable development. Energy supply systems are usually based on fossils but its shortage, the uneven distribution associated to the increasing demand has economic and environmental drawbacks. The raising on the oil prices and Climate Change concerns are new issues that led to new energy solutions and/or policies. The total of the energy-related $\mathrm{CO}_{2}$ emissions resulting from electricity generation is nearby $40 \%$ [1]. To address this issue was put the emphasis in the efficiency increase and in the increase on the use of Renewable Energy Sources (RES), considered main concerns on the present energy policies.

In modern societies the use of energy is becoming more and more common, and everyday new electric appliances reach the market contributing to raise the energy demand. Also the development of BRIC countries (Brazil, Russia, India and China) contributes to intensify this problem relying in new solutions and/or production paradigms [2]. Major energy consumers include transportation, industry, and buildings. This last is responsible for a demand of over $40 \%$.

Nowadays we have some important data allowing benchmarking by type of loads and type of use. For instance, the HVAC systems represent a significant share of the global

Manuscript received April 24, 2015; revised September 24, 2015.

M. Felgueiras and F. Martins are with the School of Engineering, Polytechnic Institute of Porto, Portugal (e-mail: mcf@isep.ipp.pt, ffm@isep.ipp.pt).

N. Cruz and R. Martins are with the Evoleo Technologies, Porto, Portugal (e-mail: 1100454@isep.ipp.pt, rodolfo.martins@evoleotech.com). energy consumed in buildings, although depending on residential or commercial building use. To know if a given load (or set of loads) has an energy consumption inside the acceptable window, it is important to have measurements of the resources involved or consumed (e.g. water, electric energy). The rational use of resources depend on several factors such type of building, users behavior and appliance performance. To achieve a reasonable consumption is a sufficient condition to select an adequate appliance with an acceptable performance. However, to assure that it runs in the adequate conditions it is a necessary condition to provide the suitable maintenance in field, otherwise the energy consumption will raise and move-out the acceptable window. To prevent this, a real-time energy monitoring is unavoidable.

However, resources infrastructures are designed for supplying a service and not often for measuring it. In the particular case of the electric power, the energy measurement of each load is particularly difficult due to the massive number of loads. This brings serious difficulties at energy data collection for the subsequent management decision actions.

This work presents an economical and feasible alternative to increase building energy performance. This paper is organized as follows: Energy issue in buildings; Measurements and monitoring model, System design and validation; Conclusion.

\section{ENERGY ISSUE IN BUILDINGS}

For many years modern life style was synonym of important amount of energy use, and as much was it use as much was the associated idea of good comfort and quality of life. The rapidly growing on energy consumption has also raised concerns about the security of supply, exhaustion of resources and environmental impacts on ozone layer depletion, global warming and climate change. To counteract this situation several measures have been proposed. Kyoto Protocol is the most known international agreement planned on a global scale to reduce greenhouse gases emissions. The European Union (EU) approved a first set of targets that were followed by a second set of new ones in the so called Europe 2020 strategy. This is a 10-year plan proposed by the European Commission in March 2010 to boost the European economy. It aims at smart, sustainable, inclusive growth with greater coordination of national and European policies. The policy identifies five headline targets the EU should take to boost growth and employment. One of the five headline goals refers to the target to reduce greenhouse gas emissions by at least $20 \%$ compared to 1990 levels or by $30 \%$ if the conditions are right, increase the share of renewable energy in 
final energy consumption to $20 \%$, and reach a $20 \%$ increase in energy efficiency. The Europe 2020 process which can help promote efficiency and a sustainable growth agenda should not be used to replace national targets and plans, especially at a time when greater transparency, comparability and commitment is required [3].

Buildings are crucial to a sustainable future as their design, construction, operation, and the activities in buildings are substantial contributors to energy-related sustainability challenges. Consequently, the reduction energy demand in buildings will play one of the most important roles in solving these challenges. Buildings activities are responsible for approximately $31 \%$ of global final energy demand, approximately one-third of energy-related $\mathrm{CO}_{2}$ emissions, approximately two-thirds of halocarbon, and approximately 25-33\% of black carbon emissions. Also energy-related problems affecting human health and productivity take place in buildings, including mortality and morbidity due to poor indoor air quality or inadequate indoor temperatures. Consequently, improving buildings and their equipment offers one of the key points to address these challenges [4]. In the EU the total amount of final energy consumption is mainly due to three sectors [5] as follows: household and services $40.3 \%$; industry $25.6 \%$; transport $31.8 \%$ (remaining 2.3 for others). In the U.S. every year, nearly half (47.6\%) of all energy produced is consumed by the Building Sector - about the same amount of energy consumed by both transportation $(28.1 \%)$ and industry $(24.4 \%)$ combined sectors [6]. As shown the share of energy consumed in buildings represents globally about $40 \%$. According to Pérez-Lombarda et al. [7] the global contribution from buildings towards energy consumption, both residential and commercial will progressively increase reaching even higher values. One important step was done by the presentation of the Energy Performance of Buildings Directive (EPBD) (2002 and recast in 2010). The EPBD addresses new buildings and those undergoing major renovation. Both its transposition and implementation have been slow. Its recast in 2009 has strengthened the Directive but less than hoped, in particular regarding to existing buildings, financing and urgency of deadlines [8]. The 2010 Energy Performance of Buildings Directive and the 2012 Energy Efficiency Directive are very important to reduce energy consumption of buildings and are the main EU legislation in this matter. However to achieve the targets established is imperative the adequate management organization based in effective consumption data.

Therefore, constant energy monitoring becomes essential, subject that will be addressed in next sections.

\section{MeAsurements AND Monitoring Model}

As seen, it is necessary to lower the energy level consumption in buildings and that relies also in the adequate data about the real consumption. Electric infrastructures are traditionally designed for supplying a service, not quantifying it. To do that it will be necessary to obtain data about each load connected to the electric grid. One possibility is the use of decentralized electric meters, connected to single loads or group of loads. At present, this solution is expensive and often tough to be economically justified. A very economical alternative consists on the use of a single energy meter located in the main electrical infrastructure input. In fact, each load has a set of characteristics that will be reflected in the grid parameters with precise values (e.g. electric current, active power). Over time, the several loads are turned on and off being obtained parameters characteristics that are a summing result of the individual loads characteristics. It is possible to make a reverse analysis, i.e. starting from the global characteristic to know when a given load is on or off.

This mean it is necessary to have direct measures from the system to obtain basis information that is later used to perform advanced operations. The proposed monitoring model is presented in the Fig. 1.

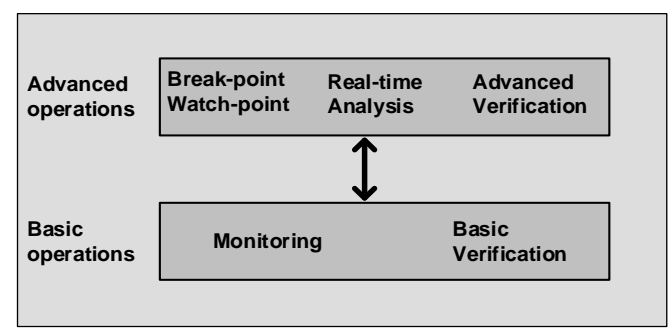

Fig. 1. Monitoring model for the electric energy analyzer.

According this model it is possible to divide all operations in two levels named Basic Operations and Advanced Operations.

The first defines the basic mechanisms to Monitoring some parameters (e.g. voltage, current or frequency). The Basic Verification results from the comparison from the monitoring data against a given threshold and using some operations (e.g., Data $>$ A; Data $=$ A, Data inside interval, etc.).

The second group of operation uses the means provided by the first level to supply advanced operations such the Watch-point, Breakpoint or Real-time Analysis. The Watch-point is a mechanism that informs another device that a given operation have a valid result (e.g. logic 1). The Break-point operation is similar but its validation has a special significance with potential catastrophic consequence and is used to stop a process. The Real-Time Analysis is used to storage a large amount of data to be used later by other operations (e.g. Advanced Verification) or analyzed later to support debug actions related with some event. This last advanced operation has a similar role than a plane black-box. Finally, the Advanced Verification results from advanced operations using data from the monitoring or the storage. Note that this model can evolve for another one that includes also Control Operations in order to be able to imposing a given state in the electric grid.

The present work is based precisely in a kind of operation that belongs to the Advanced Verification operations group. Storage data is used from the Active Power to identify when some electric loads are/were turned on or off. Later on it is possible to define others operations identifying if the power consumed by a given load is in or out there a corresponding window (e.g. a Watch-point Operation). As an example, the result can be used to signalize a bad condition in a given motor, preventing its destruction. Other example can be the energy consumed by a HVAC, identifying filters clogging. 


\section{SySTEM DESIGN AND VALIDATION}

The developed system includes two main parts: (i) the hardware and the associated software and (ii) an oriented application in a remote server that allows identifying loads. The basic principle design of the first part is presented in the Fig. 2.

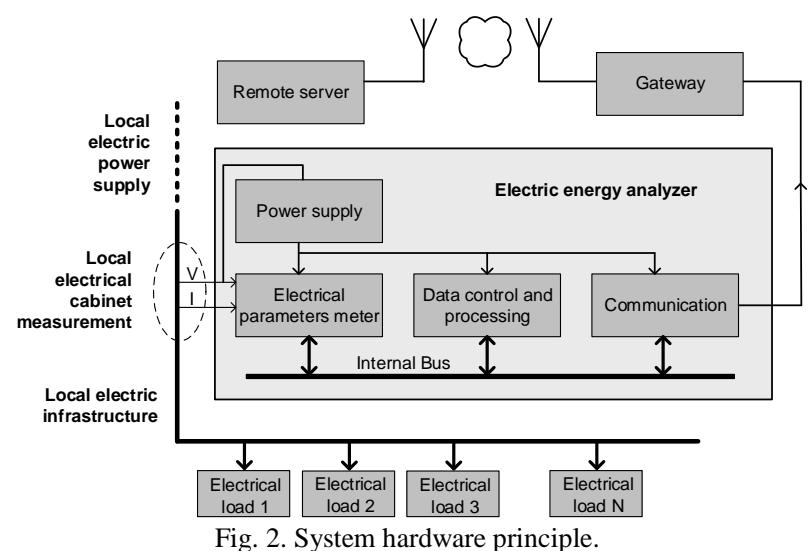

The electric energy analyzer is directly connected to the main electric power supply. The physical direct connections are only the voltage and current. As output the unit has wireless communication Wi-Fi. A remote server is able to receive all data for storage and visualization among others operations. The unit includes four internal blocs as follows:

- Power supply

- Electric parameters meter

- Data control and processing

- Communication

Power Supply is responsible for supplying the remaining blocks and has special features such a back-up battery that allows the unit to keep data in memory for periods of several days in case of power supply interruption. Several types of behaviors can be selected regarding the target installation and the battery life.

The Electrical Parameter Meter is based in an Integrated Circuit (IC) specially oriented to electrical parameters measurements [9], [10]. This component is, by itself, low cost energy analyzer with a set of important potential which makes it a preferred option for the application in question.

The Data Control and Processing is realized by the microcontroller $(\mu \mathrm{C})$ of PIC 18F47J53 - Microchip [11].

The Communication block is performed by the IC ENC424J600, which is designed with an interface Ethernet for $\mu \mathrm{C}$ equipped with a SPI serial interface or parallel port [12].

The second part consists on the development of an applet that runs in the server as depicted in Fig. 3.

Data from the energy analyzer are captured from the web. All data are stored in the Data base. Some are used by the Parameters Extraction block. In this case data from the power consumption is used to perform a verification operation. In fact each load has a well-defined behavior that can be used as an exclusive signature. The software uses the Active Power Consumption data to perform another verification operation this time to detect several positives and negatives slop transitions. The verification operation resulting data is stored in the Data Base to be after used by the Data Clustering block.
This last is responsible for associating several data in a restrict group of possibilities, each one corresponding to a specific load. They are several techniques to perform the last verification operation but the k-nearest neighbor algorithm was chosen [13]. All data are stored in the server Data Base. The system is based in a learning period of time where loads are switched on and off. Once identified the state of each load along the time, it is possible to calculate the energy consumed among other useful data.

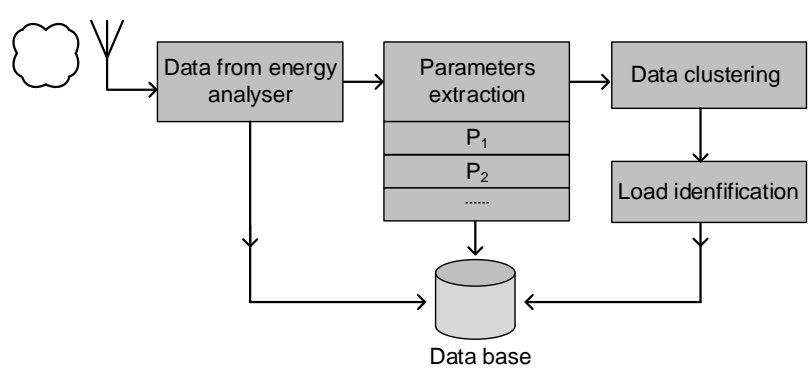

Fig. 3. Load identification principle.

The system was validated through the use of four different loads of $1000 \mathrm{~W}, 2000 \mathrm{~W}, 1500 \mathrm{~W}$ and $750 \mathrm{~W}$ further with other regular loads in the installation. The time variation of the Active Power Consumption is presented in the Fig. 4.

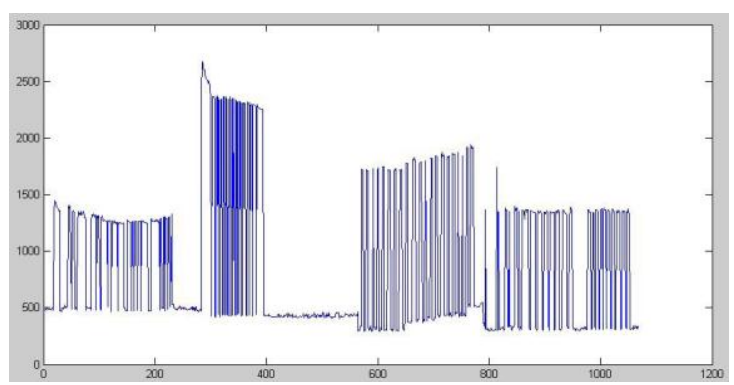

Fig. 4. Time variation for active power consumption.

As seen, the test loads are switch on and off along the period of time among others already present in the electric installation. These data are next send to the Parameter Extraction block and later to the Data Clustering. The result is presented in the Fig. 5 that represents the used parameter in function of variation on the active power consumed by each load.

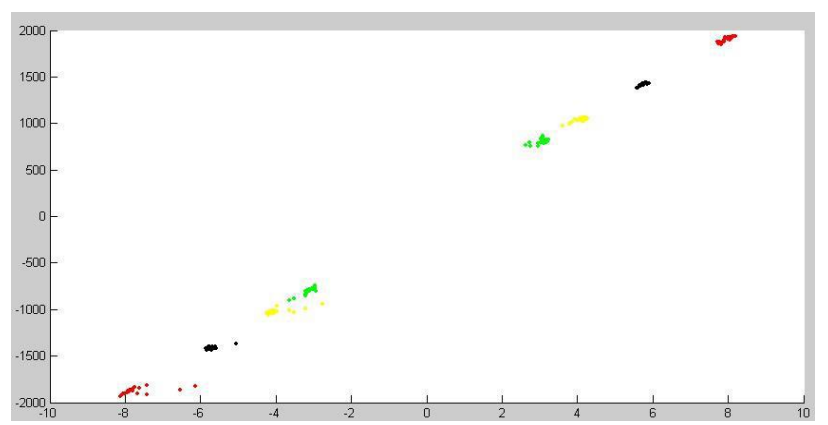

Fig. 5. Data clustering resulting from the active power.

In this figure it is possible to recognize eight groups of points in four colors, each one is associated with a specific load and each group is linked with the turn on or off for each load. As seen the system identified correctly when each one of the all four loads is switched on and off. At present state, the 
developed solution is able only to identify loads significantly different of each other, not being able to identify loads with very low consumption.

\section{CONCLUSION}

A significant share of energy produced at planetary scale is consumed in buildings and the tendency is to increase even more. Several important actions were taken to revert this situation but most of them rely in the energy measurement of each load. The decentralized energy monitoring is presently too expensive. In this work it is presented an infrastructure able to realize the load identification and the corresponding energy consumption based in a single unit located at electric main electric cabinet. Validation concept was presented as well as results from validation experiments. Major limitation identified was the inability to identify very similar loads and very low consumption loads. Future work will include the use of a large number of extracted parameter in order to improve load identification selectivity. Another important task includes the use of this solution to supervise in real-time the performance of huge loads associated with big motors such as the ones used in HVACs.

\section{REFERENCES}

[1] International Energy Agency. (February 2015). [Online]. Available: http://www.iea.org/topics/electricity/

[2] C. Felgueiras and F. Martins, "RES-Managing the unpredictability," in Proc. the $4^{\text {th }}$ International Conference on Renewable Energy Sources, Tatranské Matliare, High Tatras, Slovak Republic, 2013, pp. 179-182.

[3] Current EU Energy Saving Legislation and other Instruments, European Environmental Bureau, January 2015.

[4] D. Ürge-Vorsatz, "Energy end-use: Buildings," Global Energy Assessment - Toward a Sustainable Future, Cambridge, UK Cambridge University Press, 2012, ch. 10, pp. 649-760.

[5] European Commission, EU Energy and Transport in Figures Statistical Pocket Book, 2014.

[6] U. S. Energy Information Administration. (2014). [Online]. Available: http://www.iea.org/aboutus/faqs/energyefficiency/

[7] L. Pérez-Lombarda, J. Ortizb, and C. Poutb, "A review on buildings energy consumption information," Energy and Buildings, vol. 40, no. 3, pp. 394-398, 2008.

[8] European Environmental Bureau. (2015). Current EU energy saving legislation and other instruments. [Online]. Available: file:///C:/Users/Calos\%20Felgueiras/Downloads/FACT\%20SHEET\% $202 \% 20-\% 20$ Current $\% 20$ EU\%20Energy\%20Legislation\%20and $\% 20$ other\%20instruments\%20(10).pdf

[9] Polyphase Multifunction Energy Metering IC with Harmonic Monitoring, Analog Devices, 2012.

[10] EVAL-ADE7880EBZ Evaluation Board for ADE7880 Energy Metering IC, Analog Devices, 2013.

[11] PIC18F47J53 Family Data Sheet, Microchip, 2010.

[12] ENC424J600/624J600 Data Sheet, Stand-Alone 10/100 Ethernet Controller with SPI or Parallel Interface, Microchip, 2010.
[13] S. Sun and R. Huang, "An adaptive k-nearest neighbor algorithm," in Proc. the 2010 Seventh International Conference on Fuzzy Systems and Knowledge Discovery, 2010, pp. 91-94.

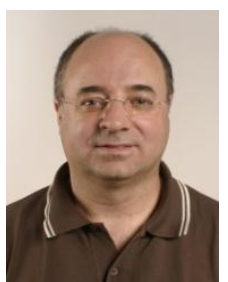

M. C. Felgueiras received the B.S. and Ph.D. degrees in electrical and computer engineering from the Faculty of Engineering, University of Porto, Porto, Portugal, in 1987 and 2008, respectively.

He started his activity in 1994 as an assistant professor and later on as an adjunct professor and researcher with the Department of Electrical Engineering, School of Engineering, Polytechnic Institute of Porto, Porto, Portugal.

His research interests at CIETI include design for debug and test of mixed-signals, remote experimentation in e-learning and renewable energy source.

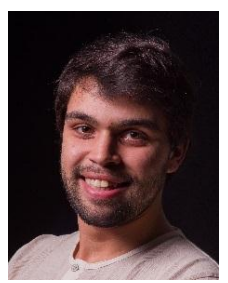

N. Cruz obtained his B.S. degree in electrical and computer engineering from the School of Engineering, Polytechnic Institute of Porto in 2013 and is presently pursuing his MSc. degree. He started his activity in 2013 as an embedded systems design engineer at Evoleo Technologies.

His research interests include electric energy management systems and electronic printed circuit boards (PCB) test.

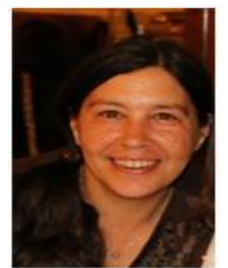

F. Martins has a Ph.D. degree in chemical and biological engineering, a master degree in environmental engineering and a degree in chemical engineering from the Faculty of Engineering, University of Porto, Porto, Portugal, obtained in 2007 , 1998 and 1989, respectively.

She had also worked in industry and nowadays is an adjunct professor at Instituto Superior de Engenharia do Porto, School of Engineering, Polytechnic Institute of Porto (IPP), Porto, Portugal.

Her research interests include sustainability, environment, energy and optimization

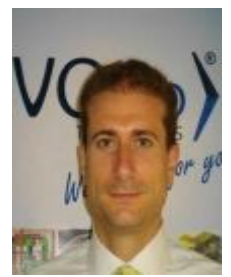

R. Martins is the general manager of Evoleo Technologies, an SME located in Maia, Portugal. Evoleo holds a multidisciplinary engineering team investing in skills related to the design of critical and complex electronic systems, embracing five areas of activity: space, transportation, energy, industry and health.

Mr. Martins has a B.Sc. degree and master degree in electrical and computer engineering in 1999 and 2003 and finished his post-graduation in the same area in 2004, being also a professor at the Electrical and Computer Engineering Department, Polytechnic Institute of Porto, from 2010 to 2012.

He started his industrial career in 1999 in the Department of Test of a production unit. Since 2003, he has been involved in the development of Hi-Rel electronics and systems for the space business, mainly with ESA projects. In 2007, the Evoleo was founded and since then, he works in the coordination and management of R\&D and innovation activities. 